\title{
Grammaticalizing adverbs of English: the case of still.
}

Diana Lewis, Aix Marseille University, Laboratoire Parole et Langage.

\begin{abstract}
The development in English of sentence adverbs, connectives and discourse markers out of VP adverbs has been the subject of a number of recent studies, many of which liken such changes to grammaticalization, involving parallel syntactic and semantic shifts or reanalyses. This paper examines the recent evolution of the English lexeme still, which has given rise to counterexpectational, concessive-connective and discourse-marking uses in addition to the older spatial and temporal ones. Shifts in position, scope and sense are traced to examine how they become correlated over time; the shifts are found to align only over long time periods. No evidence is found for any qualitative differences among the different periods in the evolution of uses of the adverb, from temporal to discoursal. The findings suggest that these shifts are gradual and context-led.
\end{abstract}

\section{Introduction}

A particularity of the Present-day English (PDE) adverb is its heterogeneity: adverbs attach to different constituent types, instantiate a wide range of meaning types and span the traditional lexisgrammar divide. In English three main sorts of adverb are traditionally identified according to the contituent modified: 'sentence adverbs' for those that modify the sentence, 'VP adverbs' for those that modify the verb phrase, and 'degree adverbs' for those that modify adjectives or other adverbs. Since Middle English, the type and token frequency of sentence adverbs has increased remarkably (Swan 1988a, 1988b). This has occurred largely through scope expansion of existing adverbs, which have undergone syntactic and semantic re-orientation, resulting inter alia in an adverbialization of speaker comment (Swan 1988a:16). This adverbialization can be seen as one facet of a wider phenomenon of information 'compression' (Biber and Clark 2002) or 'densification', especially in written English, but also in spoken language (Leech et al. 2009: 219). At the same time It exemplifies a semantic process of subjectification. ${ }^{1}$

This chapter examines recent functional splits in the English lexeme still which have resulted in counter-expectational, concessive-connective, discourse-marking and evaluative uses emerging alongside the older spatial and temporal ones. The aim is to adopt a prospective rather than a retrospective view of the expression, tracing its evolution to compare the ways in which the splits emerged, and to investigate whether and how position, scope and meaning become correlated. The question is also addressed of whether there is evidence that the different polysemies emerge by qualitatively different mechanisms. 
The next section briefly discusses the background to changes in the English sentence adverb in the Modern English period. This is followed in section 3 by a look at PDE still and in section 4 by a review of its history. Section 5 sets the findings in the context of current debates on modeling and categorizing these types of change. Section 6 provides a summary and conclusion.

\section{The development of English sentence adverbs}

Nevalainen describes adverbs as being a "weakly codified area in English grammar" (2004: 2). In fact the English adverb has long been considered an unsatisfactory category (Michael 1970, McCawley 1983), because it encompasses several different syntactic distributions and its boundaries and defining features are vague. The relations between the adverb and what it modifies -- verb, verb phrase, adjective, adverb, clause, sentence -- are varied and often vague too. Formally, the adverb spans long-established forms conserved by frequency, adverbs derived regularly via -ly suffixing, and lexicalizations (in the sense of univerbation and loss of compositionality) of phrasal adverbials.

The adverb occupies three main syntactic positions with respect to its host unit: initial, medial (i.e. pre-verbal/post-auxiliary in clauses), and final. Both sentence adverbs (SAdvs) and VP adverbs (VPAdvs) occur in all three positions, with different syntactic and semantic scopes. Many forms function as both SAdv and VPAdv. They are therefore often distinguished by their semantics rather than by their surface distribution. As Croft points out, "distributional analysis must take into consideration distributional facts RELATIVE TO THE MEANING of the words and constructions being analyzed, or else important linguistic generalizations will be missed" (2001: 73, original emphasis). Sentence adverbs thus identified are assumed to be in underlying 'peripheral' or parenthetical syntactic positions. It is therefore convenient to distinguish initial position from left-peripheral position, medial position from parenthetical position and final position from right-peripheral position (see section 3). However, the precise scope (syntactic or semantic) of a given occurrence of an adverb, and whether it is peripheral or parenthetical or not, can be hard to determine.

In the recent evolution of English adverblps, perhaps the most striking phenomenon has been the great expansion of sentence adverbs over the late Middle and early Modern English periods, as highlighted by Swan (1988a, 1991). English has seen successive rises in type frequency of three kinds of sentence adverb (Swan 1988a). First, modal adverbs such as plainly and clearly, following on from Old English, where similar 'truth intensifiers' were commonplace. After modal adverbs came evaluative adverbs such as curiously, subject-oriented adverbs such as wisely ${ }^{2}$ and, most recently of all, speech-act adverbs such as frankly. The similar rise in the number of sentence adverbs marking coherence relations is documented by Lenker (2010). Lenker terms these 'adverbial connectors' and shows that many of those that arose in the early part of the Early Modern English period have been lost, while others emerged only in Late Modern English.

Many studies have addressed the tendency for adverbs to undergo scope increase by successive reanalyses of the type VPAdv $>$ SAdv $>$ connective and/or discourse marker, both in English (e.g. Traugott and Dasher 2002, Brinton 2006) and other languages (e.g. Ramat and Ricca 1998; Fanego 2010). There is little agreement on terminology in this domain: in particular, on whether discourse connectives and discourse markers are co-terminous or distinct; or whether connectives are a subset of markers. Here we will adopt the third terminological option, whereby 'discourse marker' is a broad term including interpersonal markers such as you know and expressions of coherence relations (or rhetorical relations) such as then or even so. 
The present study focuses on the evolution of one adverb, still, and on whether and how position, scope and meaning become correlated. A further question is whether the emergence of a widescope, discourse-marking function of the adverb is qualitatively different from the emergence of other uses. These questions are addressed through a case study, based on historical corpus data, of the evolution and expansion of still over the Modern English period. ${ }^{34}$

\section{Still in Present-day English (PDE)}

Still is the seventeenth most frequent adverb in the British National Corpus at 718 per million words, just ahead of even (figures from Leech et al. 2001). There is little difference in the frequencies between the spoken $(739 \mathrm{pmw})$ and written $(715 \mathrm{pmw})$ parts of the corpus. The form still occurs today as verb, noun, adjective and adverb. It retains much of the sense of 'quiet' and 'motionless' it had in Old English, as well as occurring in a range of ossified expressions such as the still of the night, still-born, and so on. Adverbial still evolved into a range of uses, some of which have now fallen into obsolescence or occur only dialectally.

Previous studies of still have sought, from within different linguistic frameworks, to account for the semantic range of this adverb in PDE (e.g. König and Traugott 1982, Michaelis 1993, 1996, Ippolito 2004, Crupi 2006, Bell 2010). Most concur that the various PDE adverbial uses are closely linked and can be said to share a common semantic schema that is scalar. Michaelis (1993), for instance, identifies three related 'senses' for adverbial still, which she terms temporal, marginality (at the margin of a graded category), and adversative (concessive). These are exemplified in (1a), (1c) and (1d) respectively.

The examples in (1) show the range of uses that are common in present-day standard British English (PDE). They reflect a typically polysemous lexeme, where occurrences cluster in context types and clear senses can be distinguished, but where outliers make it hard to draw neat boundaries between them. Within the very broad category of adverb, different types occur. The examples in (1) include VP-adverb (VPAdv), adjective-modifying adverb (AdjAdv), sentence adverb (SAdv) and interjection. As oulined in section 2, SAdv still may occur pre-verbally as in (1d), at left periphery (LP) as in (1e) or, as part of the expression but still, at right periphery (RP) as in (1f). ${ }^{4}$

(1) a. The cat is still asleep. [temporal, VPadv]

b. A university novel is a tricky thing; an Oxford novel still trickier [comparative, AdjAdv] [The Guardian newspaper, 30/03/2012]

c. I think south east Asia still counts as Asia [temporal / marginal, VPAdv] [The Guardian newspaper, 15/05/2014]

d. My smart school still failed me [concessive-connective, SAdv] [The Guardian newspaper, 11/09/2004]

e. I shall have to stop playing golf again ... still it hasn't stopped me yet [contrastiveconcessive connective, SAdv] [BNC KC1]

f. I don't know what they've done to it to make it spread but still [contrastiveevaluative, SAdv] [BNC KBW]

g. A: "d'ya think she'll go back to work Kevin?"

[...]

B: "no .. I don't think she will to be honest with you"

A: $<$ sigh $>$

B: "still"

A: "I don't blame her" [evaluative, interjection] [BNC KBC] 
(1a) is temporal and the predicate can be glossed as 'continues to sleep'. There is usually an implicature of counterexpectation (the situation lasts longer than expected). The addition of still to a clause with a stative or durative predicate serves to emphasize the (unexpectedly long) duration. (1b) is the most clearly scalar example: it requires a gradable predicate (tricky in the example). Still introduces a higher stretch of scale with regard to some reference point that is already high: a university novel is already high on the scale of difficulty of novel-writing. (1c) is ambiguous between a temporal reading ('continues to count; i.e. has not been changed') and a far more likely marginal-concessive reading ('only just counts / counts despite being peripheral'). (1d) is concessive and counter-expectational ${ }^{6}$, as in '[smart schools are not expected to fail their pupils]; despite its being smart, my school failed me'. In (1e), still is connective, marks a contrast (cf. on the other hand, however, but) and at the same time implies speaker's positive evaluation of the idea in its scope: it expresses that being able to continue to play golf produces positive affect. The but still of (1f) provides a retrospective speaker comment signalling that the unfavourable situation just expressed is bearable or can be disregarded ( $c f$. never mind). So here again still involves counterexpectation. There may be an incipient lexicalization (from [but] [still] $>$ [but still]). An alternative analysis would be that but still is a stand-alone fragment like $(1 \mathrm{~g})$, although there is no pause before it. Finally, (1g) illustrates stand-alone still used (very much in the sense of (1f)) to mitigate any negative evaluation of the previous idea by signalling that it is less troubling than might be thought. In (1f) and (1g), then, still is becoming intersubjective, bordering on a hedging or politeness function. We suggest that it would be misleading to conceive of the 'uses' of (1e-g) as discrete. Rather, they form a cline of expression of speaker attitude (weakly positive evaluation).

As outlined above, the main types of adverbial still in PDE all involve counterexpectation of some sort. We therefore follow Michaelis (1993) in positing that the various uses of still share a common schema of counterexpectation. According to Michaelis, each sense of still "involves a particular form of expectation contravention", so that still "has a modal component: it evokes an 'expected outcome"' (1993: 196) and is scalar. Still marks an event or situation as being maintained beyond expectation, on some scale such as time, as in (1b) or affect as in (1f). While we argue for this common schema across all the different uses, there are no grounds for assuming that any one sense is 'core', or that the earliest sense or the most 'literal' sense is somehow 'basic' in the speaker's lexicon. Moreover, a common schema across members of a polysemous set such as still is unlikely to be sufficiently specific to differentiate it from other lexemes.

Michaelis further argues that "[t]he synchronic meaning links forged .. will bear no direct relation to any trajectory of semantic change. In the present case, I argue, the modern speaker has reconciled the senses of still by extracting a set of accidental yet salient semantic commonalities from these senses. The resultant generalization provides a schematic semantic structure under whose rubric all of the senses are grouped. " (1996:181). Whether or not speakers in fact make such a generalization, we agree that there is no link between the PDE speaker's representation of still and the historical evolution of the lexeme. The abstract schema, then, is posited to represent a potentially perceived commonality across PDE uses of the lexeme. From the diachronic point of view, however, the perception of a common feature may provide a clue to the cognitive mechanisms behind the semantic evolution.

Lexical adverbs like still typically can occur in the following positions with respect to the clause: pre-verbal (before the verb, between the auxiliary and the verb, or after the verb be), post-verbal (immediately after the verb), clause-final (at the end of the nuclear clause), clause-initial, at left periphery, and at right periphery. Still occurs regularly in the data in all but one of these positions: it 
does not occur at the right periphery (other than in the phrase but still) but it does occur, as seen in $(1 \mathrm{~g})$ as a stand-alone comment on the previous idea.

The next section traces the emergence of the polysemies of still over the Modern English period.

\section{Still over the Modern English period}

\subsection{Expansion of still}

Fig. 1 shows the change in token frequency of still over the Modern English period. The data on which fig. 1 is based are described in the Appendix. They were extracted from a historical corpus of British English containing informal texts (such as drama, letters and journals) that can be assumed to be as close as we can get to the spoken language of the day. The examples in this section, unless otherwise stated, are taken from this corpus, on which the description of the semantic and syntactic changes over Modern English is based. PDE examples are taken from the British National Corpus and from newspaper articles.

It can be seen from fig. 1 that, after a relatively stable period during which there may be small fluctuations in the proportions of spatial and temporal uses, the token frequency of still starts to climb in the early nineteenth century. An increase in the frequency of comparative still occurs first, followed by the appearance and gradual increase of concessive still.

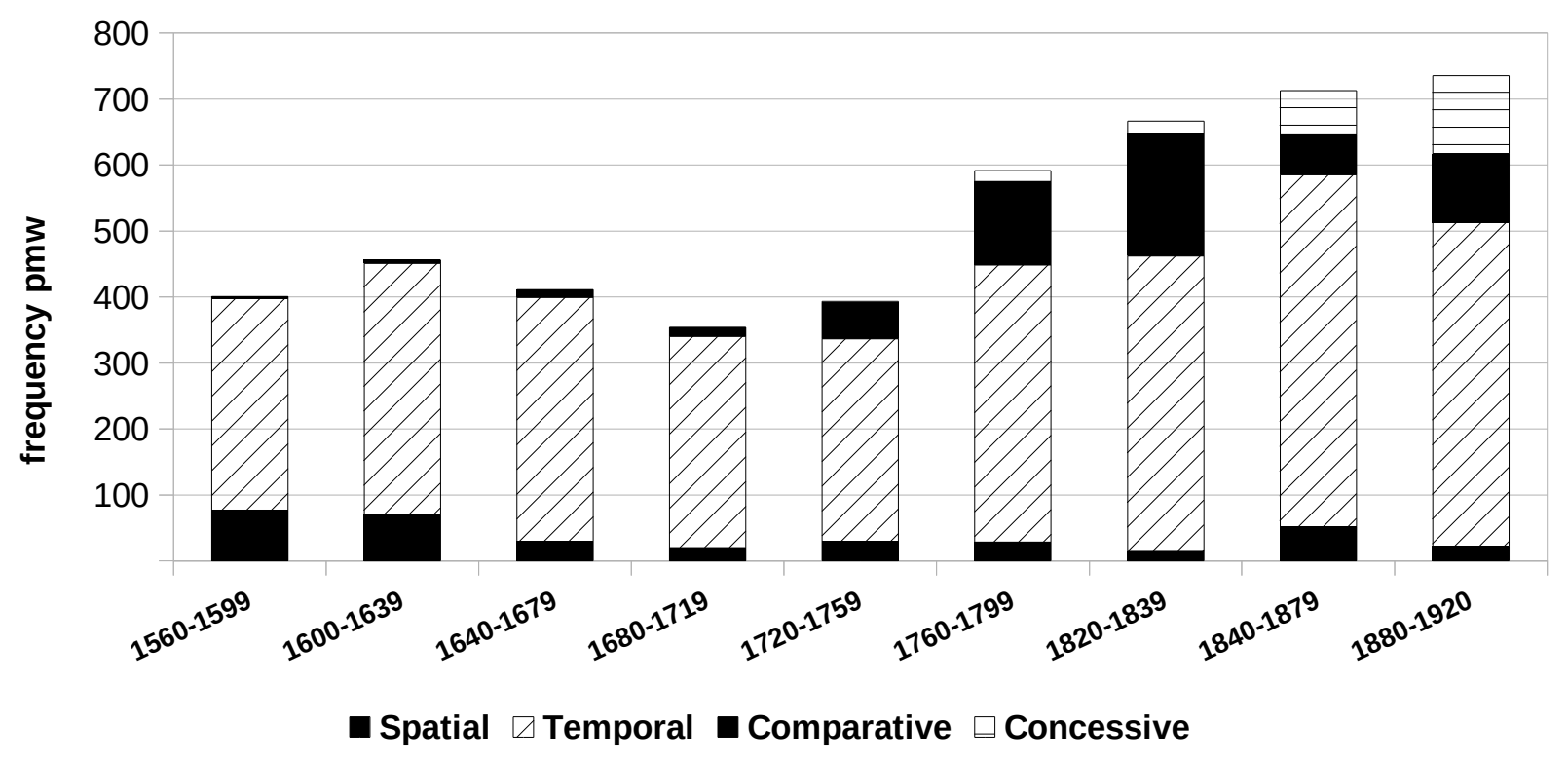

Fig. 1. Frequency of still over the Modern English period.

From a spatial meaning that dates back to Old English, still extended to temporal meaning in durative contexts. The temporal sense itself seems to have expanded to a spectrum of meaning to include the notions of 'continuously', 'constantly', 'always', 'ever'. In our data, the comparative use, which develops out of the temporal 'ever' sense, is seen to increase and then fall off, its peak being in the early nineteenth century. The concessive use emerges from the temporal by the end of the 
eighteenth century and increases in frequency over the nineteenth. The picture is largely one of successive extension of meaning and scope. The most recent developments are the left peripheral and isolate 'discourse-marking' expressions, which can be characterized as extensions of the concessive function.

We will now consider the evolution of still from the semantic and syntactic points of view. The method adopted in the semantic categorization is to avoid retrospective over-interpretation of the target item, by assuming a new reading has semanticized only where the older reading no longer makes sense ( $c f$. Heine's (2002) 'switch context' and Diewald's (2002) 'isolating context'). Semanticized connective senses often emerge only after long periods of collocation with an existing connective and/or with a particular rhetorical pattern (cf. Lewis 2014b).

The semantic expansion in the adverbial use of still can be broadly represented as (2):

(2)

$$
\begin{gathered}
\text { spatial - temporal - counter-expectational contrastive-concessive - evaluative } \\
\text { - comparative }
\end{gathered}
$$

Figure 2 sketches still over the Modern English period. Still is an interesting case to study because, perhaps due in part to its high frequency, it has continued to give rise to new polysemies while retaining most of its older range of senses.

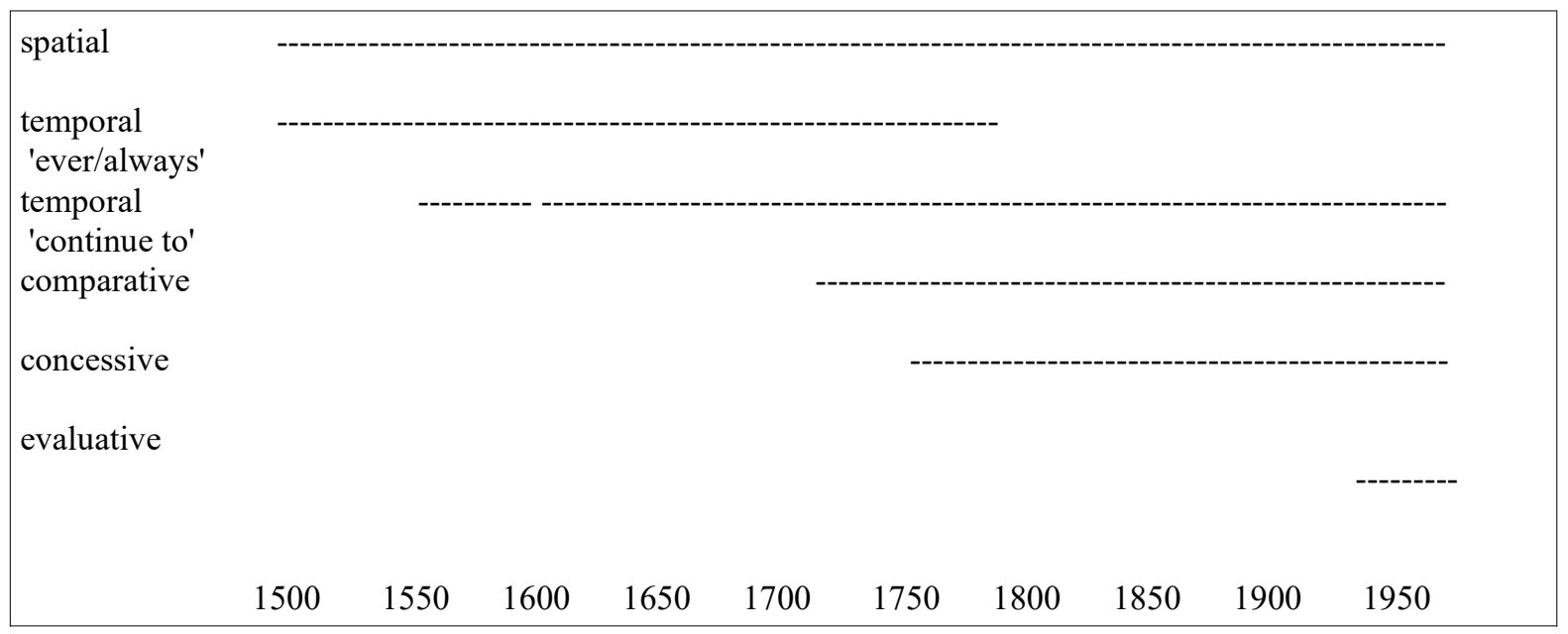

Fig. 2. Evolution of still.

The evolution overall, from space towards time and then to expectation and contrast, represents a typical shift from the physcial, spatial domain towards more abstract sense; from the objective towards more subjective, speaker-attitudinal meanings. There is also a shift from the relatively open class category of temporal adverb towards the more restricted class category of connectives. This semantic abstraction (or 'bleaching') and decategorialization are typical of grammaticalizing expressions. 


\subsection{From spatial to temporal}

The emergence of temporal still from spatial still dates back to Middle English. What we term here for convenience the spatial use of still is defined by the $O E D$ as 'at rest; motionless'. The link between the spatial and temporal notions is clear: it is durative situations and events that can be characterized as motionless. It is a natural inference from 'without motion' to 'without change'. Still naturally collocates with stative verbs: in the Paston letters of the late fifteenth century, for instance, the most common verbs with still are be, keep, and abide. Commonly found verbs in the sixteenth century are continue, endure, have, hold, last, lie, maintain, remain, stand, tarry.

By the fourteenth century at least, still has purely temporal uses where a spatial interpretation no longer makes sense. Spatial > temporal is, of course, a very typical pathway of semantic change (cf. Traugott and Dasher 2002; Heine and Kuteva 2002). The 'transition' is typically long. In the Early Modern English data, occurrences of still with verbs of position can frequently be read as spatial with a temporal implicature as in (3). There is no ambiguity; rather, the data suggest both senses obtain, with what Heine and Kuteva describe as "conceptual shift" in process (2002: 11).

stode still, and went not away [1560]

With stative verbs expressing situations and states of affairs, there is a gradual shift of meaning from stillness and quietude towards the sense of continuity, of an unchanging situation, both durative, as in (4) ('always'), and iterative, as in (5).

(4) a. but fooles will be fooles styll [c1575]

b. ..is the ready way to goe to Rye? Yes syr: Keepe still on the right hand [1586]

c. to be still his drudge while he prowles and purloynes all that I haue [c.1595]

(5) a. Fie, fie, neuer out of the kitchin, Still broyling by the fire. [1602]

b. He hath beene mooved by dyvers to appeale further, but I have styll dyswaded hym from ytt [1623]

This temporal sense of still meaning 'always', 'ever', 'constantly' or 'every time' falls into obsolescence by Late Modern English, a semantic narrowing. Still develops the more aspectual sense of 'continue to V', where the verb refers to a state or situation. But there is a vagueness across the 'ever' and the 'continue to' senses; the shift is very gradual and for many occurrences both senses can be assumed.

We turn now to the positions occupied by still. Overall the diachronic order in which positions are commonly found is:

post-verbal and clause-final $>>$ pre-verbal $>>$ clause-initial $>>$ left-periphery $>>$ isolate

The fifteenth-century data show still overwhelmingly occurring either immediately after the verb, as in $(6 a, c)$, often followed by a PP of place, or clause-finally as in $(6 b, d)$.

(6) a. I thynke best that they be styll wyth yow tyll that I speke wyth yow my-selff

b. schuld ryde to my lady of Norffolk and be wyth hyr stylle tyl we haff other tydyngys

c. and there-fore I kept stylle the bestys 
[1490s]

So-called 'adverb-preposing', whereby the default relative positions of the simplex adverb and the verb changed from verb-adverb to adverb-verb, was consolidating in the late C16th ( $v$. Rissanen 1999: 268f, Breivik and Swan 1994). With auxiliary verbs and the copula be, however, the order aux-adverb remained. The change to adverb-verb is apparent in the data for still. Of the 103 occurrences in the data for 1560-1600 that occur with a full verb, 55/103 (53\%) are pre-verb (7a) and 48/103 (47\%) are post-verb (7b).

(7) a. Yet Hermia still loves you [c.1595]

b. I frown upon him yet he loves me still [c.1595]

The data for the seventeenth century show increasing pre-verbal position amid a good deal of variability (8).

(8) The sicknes in these parts, thankes be to God, is well abated, though it lurketh still in some of our quarters. For the maintenance of those that have been and are still infected, wee have been put to lay a sesse upon the countrey, so small were the contributions of the severall parishes throughout all my Diocess, but I have now good hope that ... I shall be able to spare $50=\mathrm{li}=$. to be sent unto my Lord of London towards the help of those that are infected still in that city. [1665]

In PDE, it is the shorter and more frequent manner, time and modal adverbs, like still, that are commonly pre-verbal ( $c f$. Quirk et al 1985: 8.87). Pre-verbal position may carry less informational salience than post-verbal, but there is no evidence of semantic change correlating with the positional shift over the late sixteenth century period. The random variation seen in (8) is typical of such a change, before the word order settles into predominantly [aux] - adv - V order, but here it must be taken in the context of the broader word-order change affecting English adverbs. In PDE, the spatial adjective and the aspectual adverb are largely distinguished by word order (stay still vs. still stay), though not entirely, as final position for the adverb has not yet become obsolete.

\subsection{From temporal to comparative}

It is the now obsolete sense of 'ever / each time' that develops into the comparative use which is still current today (now somewhat old-fashioned but common in formal language). The earliest example in the data of still in a comparative context is (9).

(9) spoonefull by spoonefull: bitterer and bitterer still [1599]

From collocation with degree and quantifying expressions -- still more, 'ever more' as in (10) -there is an extension to degree. The completion of this extension becomes evident where duration no longer figures, as in (11), where the sense is one of degree only.

(10) You do not consider, Lucy, that this way is much more secure and easie, than by injurious Language to exasperate him still more, and give occasion of a lasting Quarrel for Life. [c.1696]

(11) Close to this is a still more elegant and beautiful monument [1765] 
By the mid eighteenth century the usage of still as reinforcing a comparison has developed.

Again, no correlation appears in the data between the position and the sense. And in PDE, degree still continues to occur both before (12) and after (13) the comparative adjective, depending on the informational salience.

(12) So [...] you, you think there were other facilities arose around about the same time which made the work environment still more er still better if you like? [BNC GYV]

(13) It's not a question of how good it is to recycle several tons, it would be better still not to produce it. [BNC HYJ]

Overall, the reanalysis from 'further in time' to 'further in degree' is a shift from one scale to another and illustrates the scalar nature of still.

\subsection{Counterexpectation and contrastive-concessive still}

A different set of contexts results in a counterexpectation sense. Still collocates with verbs that already contain the notion of durativity, such as remain, retain, keep, abide, dwell, last, lie, tarry, continue, dally, endure, harp after. In these contexts still can serve to reinforce the durative notion of the verb where the duration of the state of affairs is unexpected (14).

(14) a. he taryed still tyll it was nyght [1565]

b. I did within these six days see smoke still remaining of the late fire in the City. [1666]

The counter-expectational sense may start, then, as an implicature or an extension of the durative sense. The presence of still indicates that the duration is unexpected (14a), but it is a small step from there to inferring that the event itself is unexpected (14b), as the quasi-aspectual still and the verb it modifies draw conceptually closer together.

At the same time, still gains contrastive implicatures from contrastive contexts. Expression of the situation that renders the duration unexpected results in a contrastive context: two propositions linked by a coherence relation of incongruence or potential incompatibility. Such contexts open up the probability of an extension from counterexpectation to contrast (contrastive concession in this case). This type of contrastive context is illustrated in examples (15), where still makes sense as 'continue to', but where there is clearly a concessive situation, there being a degree of incompatibility between the two ideas in each case.

(15) a. A: "I told him, I lik'd not this Doing, it would not have good end"

B: "Why did you then still follow? Why left you him not?" [1571]

b. when I speake so faire: wilt stil say me nay [1575]

c. "James ... I pray yow to leave such talke." And still the said James contynewed in his raidge, bragging and swerynge [c1573]

The evolution of yet is similar to that of still, but earlier, yet being already contrastive in Middle English, from the late thirteenth century. Yet often occurs in a correlative construction as in (16a) with although. Collocation with yet $(16 \mathrm{~b}, \mathrm{c})$ and with contrastive-concessive constructions (17) strengthens the contrastivity of still. 
(16) a. although our merchantes maie have traffique thither, yet he will keape still a newtralitie [1586]

b. Yet still me thinkes the peace of the Church doeth not poize and prevaile with you as it should doe [1601]

c. so thou art alwaies asking how shal I do this and that, and yet thou remainest still ignorant [1610]

By the mid sixteenth century, the occurrence of still in contrastive-concessive constructions (17) suggests a generalized concessive implicature.

(17) a. Howsoever, doe what I can, I shalbe censur'd still [1628]

b. Nay, talk as long as you will, I shall still be of the same mind. [1679]

Semanticization of still as a purely concessive marker can be seen to have taken place once it can felicitously be used in the absence of a reasonable context for continuity, often accompanying a contrastive connective, as in (18), but also in expressions like still and all (now restricted to dialectal use).

(18) I am not so insensible of business but that I know you are hurried, but still you must admit the necessity .. [1773]

While the examples in (17) make sense as temporal ('I shall continue to be ...') with a contrastive contextual implicature, it is difficult to interpret occurrences such as (18) as temporal; still here must be interpreted as 'nevertheless'. The inference required before the shift from temporal to concessive can occur is again an expansion: if an event continues to occur, then it continues to be true that the event occurs. That is, continuity of a modal kind is inferred from the more concrete continuity.

It has been argued that scope increase from VPAdv to SAdv is likely to occur (by 'linear modification') as the result of a shift to initial position rather than while the VPAdv is in its prototypical medial position (Fischer 2007: 274-297). However, little support for this hypothesis is found with still. There is little evidence, during the long period in which concessive still slowly semanticizes, of a correlation between its position and its interpretation. Temporal still is found in initial position (19), while concessive interpretations are found in both pre-verbal (20) and initial (21) positions. The presence in (21a) of always suggests that still must be concessive.

(19) I [...] have more engagements on my Hands for a week to come.

Still my Tutor and I go on extremely well [1805]

(20) the vehicles are not quite so good as in England nor are the Horses, but both are still very tolerable [1802]

These observations suggest that position was not a determining factor in facilitating the semanticization of concession and thereby the increase in scope. The examples in (21) suggest wide-scope, left-peripheral still has become established by the mid nineteenth century. ${ }^{7}$

(21) a. There are, perhaps, few places in England, where a gentleman can be comfortably lodged and boarded at a much cheaper rate. Still there will always be many incidental expenses [1832] 
b. We have had a most splendid spring beginning with February. Still, I have been out very seldom, being afraid of treacherous winds .. [1852]

Temporal still continues in PDE to occur in initial position and in collocation with concessive yet (22) ( $c f$. example (16b)). The position functions to foreground the notion of continuity beyond expectation.

(22) Mental illness is a result of misery, yet still we stigmatise it [The Guardian newspaper, 26/02/2016]

With the modalization of still ('it continues to be true that ..') and the strengthening of the connective function, there is a shift leftwards. But medial occurrences that can hardly be interpreted as temporal show that the emergence of concessive still did not coincide with initial position or with detachment to the left periphery. In (23) still can be given a temporal interpretation (retain is a regular collocate) and the concession can be attributed to a (generalized) conversational implicature.

(23) ..following your advice as to its ornaments only in part. I still venture to retain the narrow silver round it [1790s]

But in (24), where still occurs with a non-durative verb and in the pattern though $X$, still $Y$ (which starts to replace the earlier though $X$, yet $Y$ ), a temporal reading is most ulikely (cf. example (18)).

(24) though I fear the reputation of my taste and judgment will suffer by the confession. I still must confess that I felt far more pleasure than in looking either upon Apollo or the Venus de Medicis. [1814]

Likewise, a temporal reading makes no sense of example (25).

(25) The quadrupeds, whose look, though prone, is still well suited to their form and condition [1837, OED]

In PDE, still continues to collocate with but, and continues to span both temporal and contrastiveconcessive meanings (26).

(26) A: "so that one there is ... sixes into si... thirty-six"

B: "I know .. but I still don't get what you have to write" [BNC KBJ]

Example (26) is not ambiguous (cf. example (3)) ; it is a case of dual analysis (Hankamer 1977; see section 5). Its meaning is both temporal and concessive in what is no doubt a reflection of the conceptual contiguity of these two notions. So while in PDE there are plenty of clearly temporal occurrences and clearly concessive occurrences, there has by no means yet been a clear split.

The historical data on 'marginal' still is too sparse to draw any conclusions. But it would make sense as an extension of the epistemic-modal sense.

\subsection{Evaluative still}

In PDE, an evaluative implicature has come to be attached to concessive still in particular contexts. From the beginning of the twentieth century, a sub-pattern of the concessive pattern seems to emerge, in which an undesirable, negatively-evaluated event is conceded and a less adverse, 
mitigating event is then put forward, often containing an explicit speaker stance. Initial-position concessive still constructions become correlated with positive affect on the part of the speaker. This sub-pattern is exemplified in (27). This suggests that the p still q discourse construction is conventionalizing $\mathrm{q}$ as positively evaluated by the speaker (similar to Evaluative at least (Lewis 2002).

(27) .. it is always the dregs of the population who show their patriotism by this sort of behaviour. Still, it is refreshing to see someone taking some sort of action. [1915]

As seen above, the left peripheral position of still in (27) is a recent development since the mid nineteenth century. While the difference between Still, it is refreshing and It is still refreshing may seem slight, both being concessive and connective, there is perhaps an information structural difference, so that the coherence relation of concession and the connexion to the previous idea are less salient in medial position. The fact that the still construction later on can be truncated to standalone still reveals that initial still has gradually become more peripheral, forming a separate information unit.

When still occurs alone, in reference to or in response to the previous idea, positive evaluation (and mitigation), is the default interpretation (28).

(28) A: "what a shame they've missed their walk together"

B: "yes .. still .. you just going back now are you?" (BNC, KC9)

This 'stand-alone' still again is anaphoric. It is a compact information unit: in a single word, the speaker expresses the idea that although the previously expressed state of affairs is undesirable, it is not (in the speaker's view) as prejudicial or serious as might have been implied ( $c f$. well, never mind, anyway, not to worry and other idiomatic forms expressing speaker attitude). It results from the ellipsis (more accurately, the non-expression) of the more positively valued idea that would have followed still to mitigate the previous idea. It starts as what Mulder and Thompson (2008) call a 'hanging implication', and conventionalizes to a self-contained speaker comment.

\subsection{Discussion}

Still in PDE is best analyzed as a typical case of polysemy resulting from successive functional splits as more abstract, more grammatical uses of the item emerge. But rather than thinking of the polysemies in terms of discrete 'source' and 'target' fixed notions, and of the expression undergoing reanalyses from one to the other, it may be more accurate to think of the polysemy labels as referring to generalizations across instances that come, through repetition in usage, to cluster in semantic space. The 'semanticizations' of the new polysemies of still are best conceived of in terms of this type of clustering.

The history of still shows semantic abstraction (or 'bleaching') and subjectification whereby (Traugott suggests the term 'textual subjectification' for emergent connectives (2016: 388)). It shows some decategorialization from the more open-class temporal adverb to the more closed-class connective. Still therefore exemplifies changes that are typical of grammaticalization broadly defined. Whether 'grammaticalization' refers primarily to a semantic phenomenon (increasingly grammatical meanings) or to a morphosyntactic one (increased bondedness, scope reduction or decategorialization) is largely a question of definition. The place of still in the wider context of differing models of language change will be further discussed in section 5 . 


\subsection{Still in the context of similar adverbs}

Several other English adverbs, such as yet, then, after all, even, anyway, surely, instead, at least, and so on, have likewise evolved a range of polysemies, from more concrete, lexical meanings towards more abstract, grammatical meanings. Such evolutions are well attested for other languages too (Sp. aún, todavía, Fr. encore (Mosegaard Hansen 2003), toutefois, It. tuttavia (Giacalone Ramat and Mauri 2009) etc., $c f$. Heine and Kuteva 2002).

For still, the obvious comparison to be drawn in English is with yet, which evolved a similar pattern of polysemy some two centuries earlier, and which has similarly retained older uses alongside later ones, partially retaining older word order too (v. König and Traugott 1982). Still has gradually taken over the contrastive-concessive function of yet in the correlative construction although X, yet/ still Y. Yet is becoming restricted to its use as 'until now / up until a point in time', especially as a negative polarity item, and to some idiomatized constructions. Analogy with yet may therefore have played a role in the evolution of still. (A comparable case of likely analogical change is the emergence of discourse-marking in fact (Schwenter and Traugott 2000, Lewis 2014b) along similar lines to and later than indeed.) König and Traugott emphasize the longevity of the temporal senses of yet and indeed: "the core meanings we have proposed persisted for a considerable period of time (over a thousand years in the case of yet) and ... have to a large extent constrained subsequent changes, even through several stages of grammaticalization, including the shift to nontemporal, concessive meanings" (1982: 177-8). We have rejected the notion of core meaning (section 3), but our data too support the persistence of temporal still through the emergence of the concessive construction. It may have to do with the conserving effect of high frequency (Bybee and Thompson 1997; Bybee 2010:75). Finally, the modal turn of still, whereby it implies the truth of the state of affairs it attaches to, is similar to the emergence of modal meanings in adverbs such as surely, of course, after all, anyway.

\section{Still and models of language change}

There has been some debate over the role of frequency in grammaticalization; in particular over whether frequency increases before or after a semantic shift and/or reanalysis takes place, and, if it increases before, whether it can be considered a cause of semantic change. Traugott, for example, for whom discourse markers and connectives such as concessive still emerge through grammaticalization, downplays the role of frequency, suggesting that "frequency itself appears implausible as a motivation for the onset of grammaticalization" (Traugott 2010: 280). Some studies claim to show that frequency is a direct cause of semantic change (e.g. Shibasaki 2010: 240). For Bybee, "frequency or repetition is important to this process of meaning change, not because it causes it, but because only by repetition can the change be implemented" (2011: 72). Clearly change occurs in a particular collocation or context-type, and several grammaticalization theorists have stressed that it is not the token frequency itself, but high relative frequency that can induce a meaning change; that is, the proportion of occurrences that are in the relevant collocation or context for the new meanings ( $v$. Bybee and Torres Cacoullos 2009). While many studies have centred on collocations of a grammaticlizing item with other linguistic items, cases such as temporal > concessive $>$ evaluative still, also involve collocation with a particular discourse structure or coherence relation. As mentioned earlier, table 1 is based on conservative estimates of when the comparative and concessive polysemies semanticize, so that no conclusions can be drawn about the order of frequency increase and the emergence of a new polysemy. 
The connective and evaluative uses of still are typical 'discourse-marking' functions, expressing textual relations and speaker affect respectively. Debate on the emergence of discourse markers is sometimes clouded by the instability of the terminology. This is arguably the case for the division of meaning into types. It is often claimed that the meanings expressed by discourse markers are qualitatively different from the meanings of their source expressions: markers are said to have 'pragmatic meanings' (Brinton 2006), 'procedural meaning' (Blakemore 1987, Heine 2013) or 'metacommunicative meaning' (Frank-Job 2006) as opposed to (or in addition to (Moeschler 2016)) 'conceptual meaning' or 'propositional meaning'. It is not clear from the literature exactly how the different types of meaning are thought to differ cognitively. But, on the diachronic evidence of still and many other similar expressions, the boundary between them is unlikely to be clearcut, but rather a question of degree. The other side of the 'meaning-type of discourse markers' coin is that some putative conceptual domains, such as coherence relations, politeness and hedging, speaker attitude, some types of modality, etc., are typically (not exclusively) expressed in English by short or idiomatized expressions that occur outside the nuclear clause. The language shows a clear preference for encoding such functions in compact constructions that are tacked on to a clause and are not 'addressable' (Boye and Harder 2007). Speaker attitude and coherence relations thus tend to be 'encapsulated', attaching directly to (and having scope over) the unit expressing the object of the attitude. In the case of still, this attachment is seen in both the comparative (AdjAdv) and the concessive (SAdv) uses.

There has been much debate over whether adverbial change, from VP-adverb to sentence adverb and adverbial connective or discourse marker, can be subsumed under the term 'grammaticalization' or should better be described as 'pragmaticalization' or as something else. This is largely a question of definitions of what counts as 'grammatical', of the role of the sentence in one's grammatical theory, and especially of how the semantic/pragmatic border is drawn. This last issue seems crucial. 'Pragmaticalization' implies that the items concerned become more or wholly pragmatic. But to say that discourse markers 'have' pragmatic meaning suggests that such meaning is coded into the entry for the form in the mental lexicon. We prefer to think, in more traditional terms, of semantic meaning as the coded, conventional (including Gricean conventional implicature), non-defeasible meaning and pragmatic meaning as utterance-meaning, i.e. interpretation in the individual situation. In this perspective, all morphemes have coded (semantic) meaning, and pragmatic meaning is generated in a particular utterance on a particular occasion. The interplay between the two types of meaning thus defined plays a key role in the exemplar-based theory of language change ( $v$. Bybee 2013) which offers a very plausible model of the mechanisms behind the types of gradual change attested for adverbs like still. On this view, the (coded) representations of still evolve as a function of the myriad pragmatic meanings experienced by the speaker-hearer. We avoid the term 'pragmaticalization', then, on definitional grounds to maintain the traditional semantic/pragmatic distinction. 'Grammaticalization', while not an ideal term, has the advantage of already being an umbrella term that covers a range of language change pending further evidence. A third proposal suggests that items such as connectives that operate at suprasentential level result from instantaneous 'co-optation' of a lexical item which is lifted from 'sentence grammar' and redeployed at the level of 'discourse grammar'. This is the position of Thetical Grammar (Heine, Kaltenböck and Kuteva 2011, Heine 2013, Heine, Kaltenböck, Kuteva and Long 2013), which groups at least some discourse markers and connectives with parentheticals in general. But we have seen that the data on still (and similar adverbs such as in fact (Schwenter and Traugott 2000, Lewis 2014b) and besides (Rissanen 2004)) suggest that these expressions differ from other parentheticals in that the meaning change, semantic scope expansion and extra-clausal position do not appear to occur simultaneously and suddenly. We therefore avoid the term 'co-optation' for still on empirical grounds. 
It was suggested above (section 4.4) that, as constructions with still evolve, they become subject to dual analysis by speaker-hearers for extended periods of time, during which, in the relevant contexts, the newer analysis strengthens across occurrences. The notion of dual analysis was put forward by Hankamer (1977) as a means of explanation of what now might be called constructional change. "The question of the mechanism of syntactic reanalysis -- how does a language get from one analysis of a given construction to a quite different one? -- is answered almost directly once we grant that the language may have both analyses at once." (Hankamer 1977: 603). In the same vein, Beckner and Bybee (2009) suggest that "the same word sequence may be characterized by multiple constituent structures", and furthermore "that constituency may change in a gradual fashion via usage ... and that structural reanalysis need not be abrupt" (2009: 31). This question of abruptness is relevant to our models of scope change. It is the question posed by Fanego (2004): "when a form belonging to category $\mathrm{X}$ is reinterpreted as belonging to category $\mathrm{Y}$, does this involve an abrupt change in the syntactic structure of the corresponding construction or is the change gradual?" (2004:19). Fanego's analysis of the development of the English gerund shows that reanalysis depends on "the speakers' recognition of multiple structural analyses" (2004:26); the new analyses co-existed with the old ones. This is the case for still too. Clearly the emergence in the speaker's representation of her language of a new form-meaning pair, such as the ability to use still in a nontemporal, 'mono-analysis' context, is abrupt, but it is a tiny step. Recent work in grammaticalization studies has emphasized the small-step, fine-grained nature of the shift away from the specific and lexical towards the more abstract and grammatical, and the gradual diffusion across context types. These "micro-changes", according to Traugott and Trousdale, "are discrete and, as conventionalizations, cognitively abrupt (in a tiny way) for individual speakers. However, ... changes at the level of the community are not discrete/abrupt" (2010: 23-4). Corpus data is an inadequate, at best approximate reflection of community-wide change which progresses differently across contexts and sub-communties.

\section{Conclusion}

Debate on adverbial change has been somewhat hampered by a tendency to examine discourse markers separately from other evolving adverbs and to adopt a 'backwards-looking' approach which seeks the origin of particular present-day discourse markers. The focus has tended to be on the 'output' (the discourse marker, for instance), sometimes referred to as the 'target' or the 'endpoint' of a change (e.g. Diewald 2011: 373). But these metaphors can be misleading, as language is constantly evolving and its direction, rather than being determined by targets, surely 'falls out' from the mental processes of its speakers. It is these processes that are of most interest. Adopting a more 'forward-looking' perspective to internal language change may be more suggestive of the mechanisms involved than an approach that focuses on what look like an 'origin' and an 'output' when viewed retrospectively, but which are in fact ever-evolving (sometimes vanishing) patterns of use in slowly-shifting contexts.

The findings of this study of still suggest peripheral position and discourse function did not develop simultaneously; rather, the discourse function develops first, by 'contagion' with contrastive and counterexpectational contexts and with adversative markers like but, yet and though. Particular contexts and collocations, including but still (frequent from the end of the seventeenth century, and which has arguably lexicalized in PDE as in example (1f)), would favour the gradual emergence of a concessive reading. The data suggest reanalyses of the type [but] [still $\mathrm{p}]>$ [but still] [p] $>$ [still] [p] and [although p] [yet [still q]] $>$ [although p] [yet still] [q]] $>$ [although p] [still q]]. The new analyses exist alongside the older onees, and alongside the dual analysis illustrated in (26). 
There is evidence of structural as well as semantic persistence. For instance, the comparative use retains the final position (example 13) despite the overwhelming tendency for adjective-modifying adverbs to be in Adv-Adj order. Medial position, typical of the temporal adverb, remains common for the newer concessive use, in addition to the newer left periphery position. Comparable cases also show this kind of persistence. Discourse-connective instead, for example, typically in final position before the evolution of the discourse-connective function, retains this position in addition to the newer left-peripheral position (Lewis 2014a). It appears, then, that the existing patterning of an adverb can be resistant to analogical regularization for some time after new functions emerge.

Overall, the evolution of still over the Modern English period is compatible with a broad view of grammaticalization as "extension", but not with the narrower view of grammaticalization as "increased reduction and dependency" (Traugott 2015: 60). The form runs into a delta of related uses that are seen to be diverging towards various positions on a cline of abstraction. After a period of expansion of use, a new sense settles down as the item consolidates in one or more context types. The scope increase and subjectification of adverbs such as still reflect the tendency for speaker attitude to be expressed through operators: to be 'encapsulated', attaching directly to the idea that is the object of the attitude.

Each expression has its own history, which constrains its evolution. Patterns can be sought through the careful observation of shifting collocations and discourse contexts. This is arguably best done by an approach that takes account of the polysemy as a whole. Too narrow a focus on the emergence of grammaticality or of 'discourse meanings' risks missing generalizations about language change as well as interesting differences. 


\section{Notes}

1. By subjective is meant the "way in which natural languages, in their structure and their normal manner of operation, provide for the locutionary agent's expression of himself and his own attitudes and beliefs." (Lyons 1982: 102); (cf. Traugott 1989, Visconti 2013 ).

2. See also González Alvarez (1998) on subject-oriented adverbs in Early Modern English.

3. Following the Helsinki corpus convention, we identify Early Modern English as starting around 1500 and lasting until the early eighteenth century ( $v$. Kytö 1996); Late Modern English is usually dated from the early eighteenth century to the turn of the twentieth.

4. A referee objects to the use of the word 'evolution'. 'Evolution' is chosen here for the discussions of meaning change in still in order to avoid the telic implications that come with terms such as 'development' and to emphasize that semantic shift is ongoing and internal and a by-product of usage. The choice of term also echoes fundamental work on "the evolution of grammar" (Bybee et al. 1994) and "the evolution of grammatical categories" (Heine and Kuteva 2002: 6 ) as well as more specific work on "the evolution of pragmatic markers" (Brinton 2017).

5. Issues concerning the syntactic status of peripheral and parenthetical items are beyond the scope of this paper. We fall back on the traditional division of adverbs into two syntactic categories: VP-adverbs and sentence adverbs, although the distinction is often blurred for adverbs such as 'still', and subsume left- and right-peripheral items under a broad interpretation of sentence adverbial, which may be a misnomer considering that the sentence is not the most appropriate unit of analysis for many of them.

6. Concession is often associated with counter-expectation (e.g. Rossari 2014:237) due to the incongruity inherent in concession.

7. Punctuation in historical data cannot be used as a guide to either scope or prosody. Moreover, in spoken English, the correlation between expressions regarded as syntactically parenthetical and 'comma intonation' is weak, especially for discourse markers (e.g. Wichmann et al., whose data "contradict suggestions that discourse markers tend to be prosodically separate" (2010: 36)).

\section{Appendix}

Sources for the historical corpus:

A Corpus of English Dialogues 1560-1760 (CED). 1996-2006. Compiled by Merja Kytö (Uppsala University) and Jonathan Culpeper (Lancaster University) in collaboration with Terry Walker and Dawn Archer. http://www.helsinki.fi/varieng/CoRD/corpora/CED/

A Corpus of Early English Correspondence (CEEC). 1998. Compiled by Terttu Nevalainen, Helena RaumolinBrunberg, Jukka Keränen, Minna Nevala, Arja Nurmi and Minna Palander-Collin at the Department of Modern Languages, University of Helsinki. http://www.helsinki.fi/varieng/CoRD/corpora/CEEC/index.html

The Newdigate Newsletters, transcribed and edited by Philip Hines, Jr. 1994. Part of the Icame Corpus Collection, http://clu.uni.no/icame/newdigateeks.html.

ARCHER, A Representative Corpus of Historical English Registers v. 3.2. 1990-1993/2002/2007/2010/2013/2016. Originally compiled under the supervision of Douglas Biber and Edward Finegan at Northern Arizona University and University of Southern California; modified and expanded by subsequent members of a consortium of universities. Current member universities are Bamberg, Freiburg, Heidelberg, Helsinki, Lancaster, Leicester, Manchester, Michigan, Northern Arizona, Santiago de Compostela, Southern California, Trier, Uppsala, Zurich. Examples of usage taken from ARCHER were obtained under the terms of the ARCHER User Agreement.

A Corpus of Late Modern English Texts, v.3. Compiled at KU Leuven by Hendrik de Smet with Hans-Jürgen Diller and Jukka Tyrkkö. https://perswww.kuleuven.be/ u0044428/clmet3_0.htm

Additional historical texts (letters and drama). 


\begin{tabular}{|c|c|c|c|c|c|c|}
\hline Period & Source & Words & Total & $\mathrm{n}=$ & Total & pmw \\
\hline $1560-1599$ & $\begin{array}{l}\text { CED texts } \\
\text { Other drama } \\
\text { Sermons } \\
\text { CEEC texts }\end{array}$ & $\begin{array}{l}208200 \\
23000 \\
21400 \\
104500\end{array}$ & 352000 & $\begin{array}{l}89 \\
8 \\
6 \\
38\end{array}$ & 141 & 401 \\
\hline $1600-1639$ & $\begin{array}{l}\text { CED texts } \\
\text { Other drama texts } \\
\text { CEEC texts }\end{array}$ & $\begin{array}{l}213800 \\
18000 \\
128000\end{array}$ & 359800 & $\begin{array}{l}88 \\
7 \\
69\end{array}$ & 164 & 456 \\
\hline $1640-1679$ & $\begin{array}{l}\text { CED texts } \\
\text { CEEC texts } \\
\text { Diaries }\end{array}$ & $\begin{array}{l}267000 \\
113830 \\
86500\end{array}$ & 467330 & $\begin{array}{l}92 \\
71 \\
29\end{array}$ & 192 & 411 \\
\hline $1680-1719$ & $\begin{array}{l}\text { CED texts } \\
\text { Newdigate texts } \\
\text { Diary of J Evelyn }\end{array}$ & $\begin{array}{l}304000 \\
153720 \\
5800\end{array}$ & 463520 & $\begin{array}{l}86 \\
69 \\
9\end{array}$ & 164 & 354 \\
\hline $1720-1759$ & $\begin{array}{l}\text { CED texts } \\
\text { CLMET-3 drama } \\
\text { Letters }\end{array}$ & $\begin{array}{l}228140 \\
47507 \\
143722\end{array}$ & 419370 & $\begin{array}{l}60 \\
30 \\
75\end{array}$ & 165 & 393 \\
\hline $1760-1799$ & $\begin{array}{l}\text { CLMET-3 drama } \\
\text { CLMET-3 letters } \\
\text { Archer corpus letters } \\
\text { Other letters }\end{array}$ & $\begin{array}{l}161620 \\
71000 \\
38660 \\
88900\end{array}$ & 360180 & $\begin{array}{l}76 \\
55 \\
26 \\
56\end{array}$ & 213 & 591 \\
\hline $1800-1839$ & $\begin{array}{l}\text { CLMET-3 drama } \\
\text { CLMET-3 letters } \\
\text { Other letters }\end{array}$ & $\begin{array}{l}76350 \\
74500 \\
186800\end{array}$ & 337650 & $\begin{array}{l}67 \\
42 \\
116\end{array}$ & 225 & 666 \\
\hline 1840-1879 & $\begin{array}{l}\text { Drama } \\
\text { CLMET-3 letters } \\
\text { Other letters }\end{array}$ & $\begin{array}{l}173400 \\
83820 \\
186300\end{array}$ & 443520 & $\begin{array}{l}103 \\
86 \\
127\end{array}$ & 316 & 712 \\
\hline $1880-1920$ & $\begin{array}{l}\text { CLMET-3 drama } \\
\text { Other drama } \\
\text { Journal } \\
\text { CLMET-3 letters } \\
\text { Other letters }\end{array}$ & $\begin{array}{l}125400 \\
117700 \\
11490 \\
86240 \\
179900\end{array}$ & 520730 & $\begin{array}{l}83 \\
55 \\
14 \\
64 \\
167\end{array}$ & 383 & 736 \\
\hline
\end{tabular}

\section{References}

Beckner, Clay and Joan Bybee. 2009. A usage-based account of constituency and reanalysis. Language Learning 59: 27-46.

Bell, David M. 2010. Nevertheless, still and yet: concessive cancellative discourse markers. Journal of Pragmatics 42(7), 1912-1927.

Biber, Douglas and Victoria Clark. 2002. Historical shifts in modification patterns with complex noun phrase structures: How long can you go without a verb? In Teresa Fanego, María José López Couso, and Javier Pérez Guerra (eds.), English historical syntax and morphology, 43-66. Amsterdam: John Benjamins.

Blakemore, Diane. 1987. Semantic Constraints on Relevance. Oxford: Blackwell.

Boye, Kasper and Peter Harder. 2007. Complement-taking predicates: usage and linguistic structure. Studies in Language 31(3), 569-606.

Breivik, Leiv E. and Swan, Toril. 1994. Initial adverbials and word order in English with special reference to the Early Modern English period. In Dieter Kastovsky (ed.) Studies in Early Modern English, 11-43. Berlin: Mouton de Gruyter.

Brinton, Laurel J. 2006. Pathways in the development of pragmatic markers in English. In Ans van Kemenade and Bette Lou Los (eds.), The handbook of the history of English, 307-334. Oxford: Blackwell. 
Brinton, Laurel J. 2017. The Evolution of Pragmatic Markers in English. Pathways of Change. Cambridge: Cambridge University Press.

Bybee, Joan L. 2010. Language, Usage and Cognition. Cambridge: Cambridge University Press.

Bybee, Joan L. 2011. Usage-based theory and grammatialization. In Heiko Narrog and Bernd Heine (eds.) The Oxford Handbook of Grammaticalization, 69-78. Oxford: Oxford University Press.

Bybee, Joan L. 2013. Usage-based theory and exemplar representations of constructions. In Thomas Hoffmann and Graeme Trousdale (eds.) The Oxford Handbook of Construction Grammar, 49-69. Oxford: Oxford University Press.

Bybee, Joan L. and Sandra A. Thompson. 1997. Three Frequency Effects in Syntax. Proceedings of the Twenty-Third Annual Meeting of the Berkeley Linguistics Society: General Session and Parasession on Pragmatics and Grammatical Structure, 378-388.

Bybee, Joan L. and Torres Cacoullos, Rena. 2009. The role of prefabs in grammaticization: How the particular and the general interact in language change. In Roberta L. Corrigan, Edith A. Moravcsik, Hamid Ouali, and Kathleen Wheatley (eds.), Formulaic language, vol. 1. Distribution and historical change, 187-217. Amsterdam: John Benjamins.

Bybee, Joan L., Revere Perkins and William Pagliuca. 1994. The evolution of grammar: The grammaticalization of tense, aspect, and modality in the languages of the world. Chicago: University of Chicago Press.

Croft, William C. 2001. Radical Construction Grammar: Syntactic Theory in Typological Perspective. Oxford: Oxford University Press.

Crupi, Charlene D. 2006. Structuring cues of conjunctive yet, but and still: a monosemic approach. In Joseph Davis, Radmila J. Gorup and Nancy Stern (eds.) Advances in Functional Linguisitcs, 263-281. Amsterdam: John Benjamins.

Diewald, Gabriele. 2002. A model for relevant types of contexts in grammaticalization. In Ilse Wischer and Gabriele Diewald (eds.). New Reflections on Grammaticalization, 103-120. Amsterdam: John Benjamins.

Diewald, Gabriele. 2011. Pragmaticalization (defined) as grammaticalization of discourse functions. Linguistics 49 (2), 365-390.

Fanego, Teresa. 2004. "On reanalysis and actualization in syntactic change: the rise and development of English verbal gerunds". Diachronica 21/1: 5-55

Fanego, Teresa. 2010. Paths in the development of elaborative discourse markers: evidence from Spanish. In Kristin Davidse, Lieselotte Vandelanotte and Hubert Cuyckens (eds.) Subjectification, Intersubjectification and Grammaticalization, 197-237. Berlin: Mouton de Gruyter.

Fischer, Olga. 2007. Morphosyntactic Change. Functional and Formal Perspectives. Oxford: Oxford University Press.

Frank-Job, Barbara. 2006. A dynamic interactional approach to discourse markers. In Kerstin Fischer (ed.) Approaches to Discourse Particles, 395-413. Amsterdam: Elevier.

Giacalone Ramat, Anna and Caterina Mauri. 2009. Dalla continuità temporale al contrasto: la grammaticalizzazione di tuttavia come connettivo avversativo. In Angela Ferrari (ed.) Sintassi storica e sincronia dell'italiano: subordinazione, coordinazione, giustapposizione, vol. 1, 449-470. Florence: Franco Cesati.

González Alvarez, Dolores. 1998. Evaluative subject modifiers in Early Modern English. Sederi 9, 23-38.

Hankamer, Jorge. 1977. Multiple analyses. Charles N. Li (ed.) Mechanisms of Syntactic Change, 583-607. Austin: University of Texas Press.

Heine, Bernd. 2002. On the role of context in grammaticalization. In Ilse Wischer and Gabriele Diewald (eds.) New Reflections on Grammaticalization, 83-101. Amsterdam: John Benjamins.

Heine, Bernd 2013. On discourse markers: Grammaticalization, pragmaticalization, or something else? Linguistics 51 (6): 1205-1247.

Heine, Bernd, Gunther Kaltenböck and Tania Kuteva. 2011. On thetical grammar. Studies in Language (35) 4, 852-897.

Heine, Bernd, Gunther Kaltenböck and Tania Kuteva and Haiping Long. 2013. An outline of Discourse Grammar. In Shannon Bischoff and Carmen Jeny (eds.) Reflections on functionalism in linguistics, 175-233. Berlin: De Gruyter Mouton.

Heine, Bernd and Tania Kuteva, 2002. World Lexicon of Grammaticalization. Cambridge: Cambridge University Press. 
Ippolito, Michela. 2004. An analysis of still. In Robert B. Young (ed.) Proceedings of the 14th Semantics and Linguistic Theory Conference, 127-144. Ithaca NY: Cornell University.

König, Ekkehard and Elizabeth C. Traugott. 1982. Divergence and apparent convergence in the development of yet and still. Proceedings of the Eighth Annual Meeting of the Berkeley Linguistics Society, 170-179. Berkeley, CA: University of California.

Kytö, Merja. 1996 [1991]. Manual to the diachronic part of the Helsinki Corpus of English Texts: Coding conventions and lists of source texts, 3rd edn. Helsinki: University of Helsinki.

Leech, Geoffrey, Marianne Hundt, Christian Mair and Nicholas Smith. 2009. Change in Contemporary English. A Grammatical Study. Cambridge: Cambridge University Press.

Leech, Geoffrey, Paul Rayson and Andrew Wilson. 2001. Word Frequencies in Written and Spoken English: Based on the British National Corpus. London: Longman.

Lenker, Ursula. 2010. Argument and Rhetoric. Adverbial connectors in the history of English. Berlin: Mouton de Gruyter.

Lewis, Diana M. 2002. Rhetorical factors in lexical-semantic change: the case of at least. J. E. Díaz Vera (ed.) A changing world of words: Studies in English historical lexicography, lexicology and semantics. Amsterdam: Rodopi, 525-538.

Lewis, Diana M. 2014a. Word order and the development of connective markers in English. In Laure Sarda, Shirley Carter Thomas, Benjamin Fagard and Michel Charolles (eds.) Adverbials in Use. From Predicative to Discourse Functions, 229-253. Louvain-la-Neuve: Presses Universitaires de Louvain.

Lewis, Diana M. 2014b. The emergence of discourse connectives in discourse constructions'. In Catherine Bolly and Liesbeth Degand (eds.) Across the Line of Speech and Writing Variation, , 33-49. Louvain-la-Neuve: Presses Universitaires de Louvain.

Lyons, John. 1982. Deixis and subjectivity : loquor ergo sum? In Robert J. Jarvella and Wolfgang Klein, (eds) Speech, Place and Action: Studies in Deixis and Related Topics, 101-124. Chichester: John Wiley.

McCawley, James D. 1983. The syntax of some English adverbs. Chicago Linguistic Society 19, $262-282$.

Michael, Ian. 1970. English Grammatical Categories and the Tradition to 1800. Cambridge: Cambridge University Press.

Michaelis, Laura A. 1993. 'Continuity' within three scalar models: the polysemy of adverbial still. Journal of Semantics 10:193-237.

Michaelis, Laura A. 1996. Cross-world continuity,and the polysemy of adverbial still. In Gilles Fauconnier and Eve Sweetser (eds.), Space, Worlds and Grammar, 179-226. Chicago: The University of Chicago Press.

Moeschler, Jacques. 2016. Where is procedural meaning located? Evidence from discourse connectives and tenses. Lingua 175-176: 122-138.

Mosegaard Hansen, Maj-Britt. 2003. From aspectuality to discourse marking. The case of French déjà and encore. In Ton van der Wouden, Ad Foolen and Piet Van de Craen (eds.) Particles. Belgian Journal of Linguistics 16, 2351.

Mulder, Jean and Sandra A. Thompson. 2008. The grammaticization of but as a final particle in English conversation. Ritva Laury (ed.), Crosslinguistic Studies of Clause Combining: The Multifunctionality of Conjunction, 179204. Amsterdam: John Benjamins.

Nevalainen, Terttu. 2004. Three perspectives on grammaticalization: lexico-grammar, corpora and historical sociolinguistics. In Hand Lindqvist and Christian Mair (eds.) Corpus Approaches to Grammaticalization in English, 1-31. Amsterdam: John Benjamins.

Quirk, Randolph, Sidney Greenbaum, Geoffrey Leech and Jan Svartvik. 1985. A Comprehensive Grammar of the English Language. London: Longman.

Ramat, Paolo and Davide Ricca. 1998. Sentence adverbs in the languages of Europe. In Johan van der Auwera (ed.), Adverbial constructions in the languages of Europe, 187-275. Berlin: Mouton de Gruyter.

Rissanen Matti. 1999. Syntax. Roger Lass (ed.) The Cambridge History of the English Language, vol. III: 1476-1776, 187-331. Cambridge: Cambridge University Press. 
Rissanen, Matti. 2004. Grammaticalisation from side to side: on the development of beside(s). In Hans Lindquist and Christian Mair (eds.). Corpus Approaches to Grammaticalization in English, 151-170. Amsterdam: John Benjamins.

Rossari, Corinne. 2014. How does a concessive value emerge? In Chiara Ghezzi and Piera Molinelli (eds.) Discourse and Pragmatic Markers from Latin to the Romance Languages, 237-260. Oxford: Oxford University Press.

Schwenter, Scott A. and Elizabeth C. Traugott. 2000. Invoking scalarity: The development of in fact. Journal of Historical Pragmatics 1 (1), 7-25.

Shibasaki, Reijirou. 2010. Frequency as a cause of semantic change: with focus on the second person form omae in Japanese' in An Van Linden, Jean-Christophe Verstraete and Kristin Davidse (eds). Formal Evidence in Grammaticalization Research, 225-243. Amsterdam: John Benjamins.

Swan, Toril. 1988a [1986]. Sentence Adverbials in English: A Synchronic and Diachronic Investigation. Oslo: Novus Forlag.

Swan, Toril. 1988b. The development of sentence adverbs in English. Studia Linguistica 42(1), 1-17.

Swan, Toril. 1991. Adverbial shifts: evidence from Norwegian and English. In Dieter Kastovsky (ed.) Historical English Syntax, 409-438. Berlin: Mouton de Gruyter.

Traugott, Elizabeth C. 1989. On the rise of epistemic meanings in English: an example of subjectification in semantic change. Language 65, 31-55.

Traugott, Elizabeth C. 2010. Grammaticalization. In Silvia Luraghi and Vit Bubenik (eds.) Continuum Companion to Historical Linguistics, 269-283. London: Continuum Press.

Traugott, Elizabeth C. 2015. Toward a Coherent Account of Grammatical Constructionalization. In Jóhanna Barðdal, Elena Smirnova, Lotte Sommerer and Spike Gildea (eds.) Diachronic Construction Grammar, 51-79. Amsterdam: John Benjamins.

Traugott, Elizabeth C. 2016. Identifying micro-changes: the case of subjectification. In Merja Kytö and Päivi Pahta (eds.) The Cambridge Handbook of English Historical Linguistics, 376-389. Cambridge: Cambridge University Press.

Traugott, Elizabeth C. and Richard Dasher. 2002. Regularity in semantic change. Cambridge: Cambridge University Press.

Traugott, Elizabeth C. and Graeme Trousdale. 2010. Gradience, gradualness and grammaticalization: How do they intersect? In Elizabeth C. Traugott and Graeme Trousdale (eds.) Gradience, Gradualness and Grammaticalization, 19-44. Amsterdam: John Benjamins.

Traugott, Elizabeth C. and Graeme Trousdale. 2010. Gradience, gradualness and grammaticalization: how do they intersect? In Elizabeth C. Traugott and Graeme Trousdale (eds.) Gradience, Gradualness and Grammaticalization, 19-44. Amsterdam: John Benjamins.

Visconti, Jacqueline. 2013. Facets of subjectification. Language Sciences 36, 7-17.

Wichmann, Anne, Anne-Marie Simon-Vandenbergen and Karin Aijmer. 2010. How prosody reflects semantic change: A synchronic case study of of course. In Kristin Davidse, Lieven Vandelanotte and Hubert Cuyckens (eds.) Subjectification, Intersubjectification and Grammataicalization, 103-154. Berlin: Mouton de Gruyter. 